\title{
EDUCAÇÃO E AUTONOMIA: PERSPECTIVAS ROUSSENIANAS PARA O ENSINO
}

\author{
Ana Maria Siqueira Silva ${ }^{1}$ \\ Evandson Paiva Ferreira ${ }^{2}$ \\ Régis Lopes Silva ${ }^{3}$
}

\begin{abstract}
Resumo: Neste artigo destacamos a noção de autonomia presente na filosofia de Rousseau. Tomamos como objeto de reflexão quatro obras deste autor: o Primeiro e o Segundo Discurso, O contrato social e o Emílio. É nesta última obra, toda ela dedicada à formação humana, que Rousseau expóe sua pedagogia filosófica, destacando que qualquer ideia de transformaçáo social passa necessariamente pela transformação do homem. E cabe à educação, entendida não como mera escolarização, mas como verdadeiro processo de formaçáo humana, moral e intelectual, esse importante papel político. Desse modo, o estudo de Rousseau mostra sua atualidade na medida em que nos faz por em questáo, mais uma vez, os fins da educação. Deixar-se provocar pelo pensamento filosófico de Rousseau, pondo em questão o homem, a sociedade, os valores, as instituiçôes, a educação, faz parte do exercício da autonomia.
\end{abstract}

Palavras-chave: Filosofia. Educação. Política. Autonomia.

\section{EDUCATION AND AUTONOMY: ROUSSEAUNIAN PERSPECTIVES FOR TEACHING}

\begin{abstract}
In this article we highlight the notion of autonomy present in Rousseau's philosophy. We take as object of reflection four works of this author: The First and The Second Discourse, The Social Contract and Emílio. It is in this last work, all devoted to human formation, that Rousseau
\end{abstract}

1 Ana Maria Siqueira Silva (Mestranda) PPGEEB (Programa de Pós Graduação Ensino na Educação Básica - Mestrado) CEPAE (Centro de Ensino e Pesquisa Aplicada à Educação)/ UFG (Universidade Federal de Goiás). anasiqueira4@gmail.com

2 Evandson Paiva Ferreira (Orientador) PPGEEB (Programa de Pós Graduação Ensino na Educação Básica - Mestrado) CEPAE (Centro de Ensino e Pesquisa Aplicada à Educação)/ UFG (Universidade Federal de Goiás). evandsonpaivaferreira@gmail.com

3 Régis Lopes Silva (Mestrando) PPGEEB (Programa de Pós Graduação Ensino na Educação Básica - Mestrado) CEPAE (Centro de Ensino e Pesquisa Aplicada à Educação)/UFG (Universidade Federal de Goiás).regislopes@gmail.com 
exposes his philosophical pedagogy, emphasizing that any idea of social transformation necessarily passes through the transformation of man. And it is a function of education, understood not as mere schooling, but as a true process of human formation, moral and intellectual, this important political role. In this way, Rousseau's study shows its present character to the extent that it makes us once again place a big question mark on the goals of education. Letting oneself be provoked by Rousseau's philosophical thinking, calling into question man, society, values, institutions, education, is part of the exercise of autonomy.

Keywords: philosophy, education, politics, autonomy.

\section{INTRODUÇÃO}

Embora Rousseau não tenha vivido e visto as consequências da Revolução Industrial, foi testemunha de importantes mudanças em marcha no século XVIII. Prova disso são seus textos, que já provocavam a reflexão sobre o modo como o homem organizava a vida social, toda ela sustentada nas conveniências pessoais e exploração do homem e da natureza. Para Rousseau estava claro que o progresso queria dizer progresso material, e que este, por si só, não fazia do homem um indivíduo melhor, mais virtuoso, não trazia um "progresso" moral. A virtude humana não pode ser fundamentada no conhecimento, mas na capacidade do homem em pensar criticamente e praticar ações justas. A distinção kantiana entre conbecer e pensar nos ajuda a compreender esse aspecto da reflexão rousseauniana. Em A Crítica da Razão Pura, Kant faz uma distinção entre o que é pensar e o que é conhecer (Cf. Arendt, 2000, p. 13; Vallée, 1999, p. 37-38). O conhecimento é o resultado de uma experiência, de uma verificação no mundo empírico, é de natureza científica (tal como temos entendido nos últimos séculos sobre o que é ciência), produz "resultados". Já a faculdade de pensar não conhece, não produz resultados empíricos, não "progride". Instigado pela opacidade da realidade em que vive, o homem que pensa, interroga o mundo, as suas instituições, os seus valores, buscando encontrar alguma transparência que revele o real. Nesse sentido, a obra de Rousseau se situa no plano do pensamento, e talvez isso explique muito da incompreensão e das críticas infundadas que sofreu e ainda sofre, uma vez que a modernidade se interessa mais pelo conhecer do que pelo pensar.

\section{DESENVOLVIMENTO}

Rousseau não se ocupa apenas em informar o que considera ser o justo e o verdadeiro, mas seu filosofar provoca uma verdadeira formação, uma Paideia filosófica, dando àqueles que com ele partilham o exercício do pensamento, a liberdade para exercer, na prática, sua autonomia.

Numa sociedade ora denominada sociedade do conhecimento, ora sociedade do espetáculo (se bem que ambas representam o mesmo "estado de espírito" da sociedade desde o século XX), Rousseau provoca-nos a continuar a interrogar a sociedade em que vivemos, sociedade esta cada vez mais vazia de sentido, sem disposição de por para si a responsabilidade em pensar seu destino. Esvaziamento este que não escapa aos discursos educacionais vigentes, eivados de conceitos que 
nada dizem ou que, na expressão de José Sergio Carvalho, não são mais do que "anemia semântica." (2013, p.14) Talvez sejamos mais uma sociedade do esquecimento do que qualquer outra coisa, onde o "espetáculo serve para facilitar e encobrir esse esquecimento." (Castoriadis, 2006, p. 257) Rousseau nos ajuda a romper com o fechamento das significações que tem marcado a existência idiota (idios) do indivíduo privatizado (Cf. Arendt, 2009; Castoriadis, 1992), reduzido à satisfação das necessidades materiais e interesses privados.

O século XVIII, época na qual Rousseau viveu, foi o século das Luzes. O centro desse movimento pode ser encontrado na concepção que a civilização da Ilustração (Cf. Vaz, 2004, p. 85) tinha de homem e de história. Embora herdeiro da tradição filosófica que se constituiu a partir do renascimento e retomando o caráter racional de projeto de autonomia, criado pelos gregos na Antiguidade, o Iluminismo (também denominado de Ilustração ou Esclarecimento) rompe com a tradição cristã, pondo definitivamente o homem como o centro da história. Contudo, a grande criação desse período é a ideia de progresso.

O século XVIII vê nascer novas ideias fundamentadas na nova concepção de homem e de Razão, como a defesa da tolerância religiosa e os direitos naturais do homem e do cidadão. Nesse período foram rejeitados todos os sistemas metafísicos medievais que ainda existiam. À religião foram dirigidas severas críticas identificando nessa instituição tudo aquilo que a Ilustração se opunha e combatia: superstições, preconceitos, privilégios, tirania, enfim, tudo o que constituía a chamada idade das trevas. Embora muitos estudiosos no século XX tenham mostrado que esse termo também é um outro tipo de preconceito (Cf. Le Goff, 1993), é preciso compreendê-lo a partir de necessidade do iluminista em se diferenciar e romper com o pensamento religioso medieval. O filósofo iluminista pensava que a crença religiosa impedia a autonomia do pensamento, pois ao acreditar numa realidade extra-social tirava do homem a responsabilidade pelas suas ações e justificava a organização da vida social a partir de uma ordem sobrenatural. Contudo, tanto a censura religiosa quanto a política foi eficiente em muitos momentos, silenciando intelectuais e comprometendo a divulgação de novos saberes. Rousseau também fora vítima desse poder de silenciar o intelectual em vários momentos de sua vida.

Esse movimento de ideias, malgrado a especificidade do pensamento de cada intelectual iluminista, dirigiu sua crítica radical aos fundamentos da cultura europeia, a qual preservava em muitos aspectos, sejam políticos ou econômicos, a velha ordem medieval. O Iluminismo surgiu numa Europa onde o analfabetismo beirava 63\% (Cf. Gusdorf, 1971, p. 466) e que a maioria da sua população era rural. Fenômeno cultural cujas raízes brotam da nova classe social emergente, a burguesia, o Iluminismo se constituiu num movimento pela emancipação humana. Sapere aude! foi o lema desse período, definido por Kant

a saída do homem da sua menoridade, da qual ele próprio é culpado. A menoridade é a incapacidade de fazer uso de seu entendimento sem a direção de outro indivíduo. O homem é o próprio culpado dessa minoridade se a causa dela não se encontra na falta de entendimento, mas na falta de decisão e coragem de servir-se de si mesmo sem a direção de outrem. Sapere aude!'Tem coragem de fazer 
uso de teu próprio entendimento, tal é o lema do esclarecimento [Auflelärung]. (Kant, 2009, p. 63-64)

Nesse cenário filosófico, Rousseau foi quem, sendo um dos iluministas, fez a crítica aos novos mitos que o movimento iluminista carregava, principalmente o mito do progresso e do racionalismo exagerado. Rousseau foi capaz de perceber que o mundo novo prometido não passava de uma quimera, visto que estava fundado numa desordem individual e social. Situado no Iluminismo, é de dentro deste movimento intelectual que irá fazer a sua filosofia de paradoxos, obra muitas vezes taxada de romântica devido ao modo como expressa seu pensamento.

$\mathrm{O}$ aspecto específico e peculiarmente novo que Rousseau proporcionou à sua época parece residir no fato de libertá-la do domínio do intelectualismo. Às forças do entendimento reflexivo nas quais se baseava a cultura do século XVIII, ele opõe a força do sentimento; perante o poder da "razão" que examina e disseca, ele se torna o descobridor da paixão e de sua energia primitiva elementar. $\mathrm{Na}$ realidade foi uma torrente completamente nova de vida que assim penetrou na espiritualidade francesa, ameaçando dissolver todas as suas formas fixas e transbordar os seus limites cuidadosamente estabelecidos. (Cassirer, 1999, p. 81)

Para Cassirer, Rousseau foi o primeiro pensador a questionar a segurança e abalar os alicerces do século XVIII, levantando questões que, ainda hoje, são pertinentes, uma vez que ainda não estão resolvidas. "Mesmo que sua formulação com frequência seja para nós apenas historicamente significativa e compreensível, o seu conteúdo não perdeu nada de sua proximidade." (Cassirer, 1999, p. 39) O que Rousseau espera da comunidade humana não é que garanta e aumente a felicidade do homem, nem seu bem-estar ou prazeres, mas que assegure a liberdade. A base da vida social é verdadeiramente na consciência da liberdade e na ideia do direito que esta consciência exige. É a liberdade que possibilita ao homem a prática de ações autônomas e justas.

O Primeiro e o Segundo Discursos são duas obras que se apresentam como um radical protesto contra todas as sociedades instituídas. Com isso, Rousseau não apresenta um projeto de reforma social que corrija tais desigualdades. O que apresenta ao seu leitor é um projeto muito mais ousado, visto que vislumbrar uma sociedade justa implica uma nova instituição social, uma outra sociedade, cujos fundamentos garantam uma verdadeira comunidade ética e política. A busca dessa nova forma comunitária será o objeto de reflexão d'O contrato social.

E possível encontrar autores que veem uma descontinuidade entre $O$ contrato social e os escritos anteriores de Rousseau, como se essa obra contradissesse a estrutura do pensamento rousseauniano. Neste livro o filósofo retoma os conceitos que foram tratados no Discurso sobre a desigualdade, reafirmando que viver em sociedade é viver sob ferros, vigiado, imerso na opacidade das aparências. O objeto d'O contrato é encontrar os fundamentos da convenção, estudar a natureza fundante da sociedade civil, e mostrar que, diferentemente de Hobbes e Locke, o direito social não nasce no estado de natureza. 
Desta maneira, apesar de todos os antagonismos aparentes, o Discurso sobre a origem da desigualdade e o Contrato social coadunam-se e complementam-se. Ambos contradizem-se tão pouco que só se pode explicar um a partir do outro e um através do outro. Quem considera o Contrato social um corpo estranho na obra de Rousseau, não compreendeu a organicidade espiritual dessa obra. Todo interesse de Rousseau e toda a sua paixão fazem parte de um modo ou de outro da doutrina do homem, mas ele compreendeu agora que a questão "o que o homem é" não pode ser separada da questão "o que ele deve ser". (Cassirer, 1999, p. 64)

Rousseau mais uma vez quer convencer que o homem é naturalmente bom, mas historicamente mau. No seu método de exposição, seguindo o que fizera nos escritos anteriores, ele começa por afastar todos os fatos, a história, visto que esta é marcada pela alienação. A questão central é a democracia moderna, a relação do indivíduo com a sociedade, de tal modo que este indivíduo seja capaz de se submeter autonomamente à sociedade, alienação da vontade individual à vontade geral, um ato da vontade esclarecida, ação política, segundo a necessidade política. A alienação que no Segundo Discurso ganhava forma no discurso do demagogo, n'O contrato ganha um outro sentido. Se naquela obra a alienação significava renúncia à própria liberdade, renúncia "à qualidade de homem, aos direitos da Humanidade, inclusive seus deveres" (Rousseau, 1978 ,p. 26) nesta, a alienação garantirá a liberdade individual. Para tanto, Rousseau se propõe a "Encontrar uma forma de associação que defenda e proteja de toda a força comum a pessoa e os bens de cada associado, e pela qual, cada um, unindo-se a todos, não obedeça portanto senão a si mesmo, e permaneça tão livre como anteriormente." (Rousseau, 1978, p. 30) Segundo Cassirer, este é o centro de todo o problema político-social, a questão da liberdade e da vontade geral. Os homens trocam a liberdade e a independência do estado natural pela verdadeira liberdade, a ligação de todos com a lei, tornando-se, desse modo, personalidades autônomas.

Aí reside o núcleo de todo o problema político-social. Não se trata de libertar e emancipar o indivíduo no sentido de que ele seja expelido da forma e da ordem da comunidade; ao contrário, trata-se de encontrar uma forma comunitária que proteja com toda a força concentrada da associação estatal a pessoa de cada indivíduo, e o indivíduo, unindo-se aos outros, obedeça apenas a si mesmo, apesar de fazer parte dessa união. (Cassirer, 1999, p. 56)

Importante não confundir vontade geral com vontade individual ou vontade de todos. Enquanto esta representa o interesse particular, aquela representa o interesse público. A divisão entre o público e o privado, estabelecido pela primeira vez na pólis grega, tendo no interesse público a razão de ser da vida política, na modernidade acabou sendo invertida, tendo os interesses privados a prioridade nos negócios públicos. Rousseau vê que uma sociedade que privilegia o privado em detrimento do interesse público contamina todas as relações sociais e põe em risco a vida coletiva. Com isso, assume a reflexão de como a vontade geral irá prevalecer frente à vontade individual.

Há muitas vezes grande diferença entre a vontade de todos e a vontade geral: esta olha somente o interesse comum, a outra o interesse privado, e outra 
coisa não é senão a soma de vontades particulares; mas tirai dessas mesmas vontades as que em menor ou maior grau reciprocamente se destroem, e resta como soma das diferenças a vontade geral. (Rousseau, 1978, p. 41)

Para continuar seus argumentos, Rousseau dá outro sentido para expressões do vocabulário político, reestabelecendo o papel do governo e a relação entre o súdito e o soberano. Se era lugar comum identificar o povo como súdito e a lei, ou quem a exercia, como o soberano, no pensamento rousseauniano o povo é o soberano, no sentido de estar esclarecidamente submisso à lei. É a lei que exerce a soberania. Se soberana é a lei, o povo é soberano na lei. Esse novo pacto social, fundado na vontade geral, é que irá buscar a forma mais justa de vida social. Rousseau não oferece nesta obra um modelo, uma receita, mas um caminho de reflexão cujos conceitos podem iluminar a ação política e redefinir o lugar do cidadão na nova ordem social. Para Cassirer, a originalidade de Rousseau está no fato de que,

Em parte alguma o Estado é concebido por Rousseau como mero Estado de bem-estar social; para ele o Estado não é simplesmente o "distribuidor de bem-aventuranças", como para Diderot e a maioria dos enciclopedistas. Por isso, não garante ao indivíduo a mesma proporção de bens, mas assegura-lhe exclusivamente a proporção equilibrada de direitos e deveres. Por conseguinte, está autorizado e habilitado a intervir na propriedade à medida que a disparidade da posse coloque em perigo a igualdade dos sujeitos jurídicos - e condene classes isoladas de cidadãos à completa dependência econômica ameaçando assim tornar-se um joguete nas mãos dos ricos e poderosos. (Cassirer, 1999, p. 60)

Cassirer destaca também a ideia defendida por Rousseau que a mudança do Estado precede a mudança do indivíduo. Ideia esta que atravessa toda uma concepção de educação pública, uma vez que se educam os homens porque há uma sociedade que os forma na perspectiva de que estes a continuarão. Com isso, Rousseau mais uma vez rompe com um lugar comum do ideário moderno, o de pensar o indivíduo anterior à vida social, e põe em xeque também muito do que foi objeto de crítica em seu pensamento, isto é, a ideia de que este filósofo pensa o homem e a sua educação em detrimento da sociedade.

Escrito na mesma época que $O$ contrato social, em 1762, O Emílio será a obra em que Rousseau se dedicará a pensar a educação do indivíduo, tendo como fio condutor a felicidade do homem, a qual deve ser encontrada no equilíbrio entre vontade e poder. Não se trata de um manual pedagógico de como educar o indivíduo, mas é uma reflexão filosófica sobre o que é e qual o sentido da educação em vista da formação do homem livre e feliz. Para que uma educação nesses moldes possa um dia existir, Rousseau apela para o reconhecimento e respeito à liberdade das crianças e dos homens. Formar homens livres implica necessariamente reconhecer e tratá-lo como ser livre já durante o processo de formação. Rousseau chama atenção para a confusão que a palavra liberdade pode gerar, sendo muitas vezes confundidas com o ceder às vontades e desejos da criança. Para ele, uma educação que se submete a tal situação não forma indivíduos livres, capazes de orientar-se 
autonomamente na vida social, mas escravos de seus desejos, fazendo também de quem está à sua volta seus escravos.

Rousseau sabe que a educação do humano escapa aos esquemas teóricos que procuram determinar a priori o método mais adequado de formar o homem. Como a educação está situada no campo da liberdade, tanto da liberdade de quem é educado como daquele que educa, seja pai ou mestre, "pois quem pode esperar dirigir inteiramente as palavras e as ações de todos os que rodeiam uma criança?" (Rousseau, 2004, p. 09). Ele define a educação como uma arte, e que por esta razão, "é quase impossível que ela tenha êxito, já que o concurso necessário a seu sucesso não depende de ninguém. Tudo o que podemos fazer à custa de esforços é nos aproximar mais ou menos do alvo, mas é preciso sorte para atingi-lo." (Rousseau, 2004, p. 09)

Neste livro Rousseau cria um aluno hipotético, o Emílio, um aluno perfeito, com boas condições físicas e intelectuais, o aluno que quer aprender, que "enfrenta" os problemas de um aluno real. Rousseau pensa que a sociedade, do modo como está instituída, não forma. Pelo contrário, deforma. A retirada desse aluno da vida social se justifica na ideia de que educamos as crianças e os jovens não para a sociedade tal como ela é, mas de como ela pode vir a ser, de preferência mais justa e feliz. Estar fora da sociedade possibilita um admirar, um distanciamento crítico, que melhor educa o juízo. "Emílio não é um selvagem ao ser relegado aos desertos: é um selvagem feito para morar nas cidades. É preciso que saiba encontrar nelas o necessário, tirar partido dos habitantes e viver, senão como eles, pelo menos com eles." (Rousseau, 2004, p. 278)

Rousseau, embora comece o livro situando-o no tempo histórico, põe a formação de Emílio no tempo lógico, organizando uma ordem de razões que se constituem como crítica radical a qualquer tempo histórico e à pretensão deste em educar os indivíduos. A educação do Emílio se constituirá numa "medida" para as outras formas de educação.

"Viver é o ofício que quero ensinar-lhe." (Rousseau, 2004, p. 15). Desde o início do livro, Rousseau já distingue um outro fim (télos) para a educação, não a reduzindo a formar para esta ou aquela habilidade específica, mas para a vida, para as diferentes situações que nos são impostas ao longo de nossa existência. "Não se trata de ensiná-la a suportar as dificuldades, mas de exercitá-la ao longo da vida." (Rousseau, 2004, p. 16)

Viver não é respirar, mas agir; é fazer uso de nossos órgãos, de nossos sentidos, de nossas faculdades, de todas as partes de nós mesmos que nos dão o sentimento de nossa existência. $O$ homem que não viveu não é o que contou maior número de anos, mas aquele que mais sentiu a vida. Tal homem foi enterrado aos cem anos e estava morto desde o nascimento. Melhor seria ir para a tumba na juventude, se pelo menos tivesse vivido até essa idade. (Rousseau, 2004, p. 16)

Para Cassirer a ideia fundamental d'O Emilio é a educação para o saber viver, para a autonomia e a independência da vontade e do caráter: 
A ideia fundamental do Emílio é de que não se deve eliminar nenhuma dificuldade física da aprendizagem do pupilo que se quer educar para a independência da vontade e do caráter - e que não se deve poupá-lo de nenhum sofrimento, esforço ou privação. A única coisa da qual se deve cuidadosamente protegê-lo é da imposição violenta de uma vontade alheia de um preceito que ele não entende em sua necessidade. Desde a mais tenra infância, ele deve conhecer a coação das coisas, e aprender a curvar-se diante dela, mas deve ser poupado da tirania dos homens. (Cassirer, 1999, p. 61-62)

Rousseau não poupa críticas à educação dada às crianças em sua época. Denunciou o que chamou de "tortura" a que as crianças eram submetidas desde o nascimento. Não apenas o corpo era moldado e desfigurado, mas também o caráter, sendo desde cedo habituado a se submeter aos constrangimentos que the são impostos. "Os primeiros presentes que se recebem de vós são correntes; os primeiros cuidados que recebem são torturas." (Rousseau, 2004, p. 19) Rousseau redefine não só a educação e os cuidados com as crianças, mas a própria noção do que é a infância. Desde o final da idade média a visão do infante como um adulto em miniatura vinha sendo substituída pela compreensão que a criança tem um modo de ser específico. Rousseau faz parte dessa tradição, pois sabe que "A infância tem maneiras de ver, de pensar e de sentir que lhe são próprias (...)" (Rousseau, 2004, p. 91) Ele deu uma importante contribuição ao denunciar o "costume desnaturado" (Rousseau, 2004, p. 18) com que as crianças eram tratadas desde o nascimento, chamando os pais, em especial as mães, à responsabilidade de educadores. "Se as mulheres voltarem a ser mães, $\operatorname{logo}$ os homens voltarão a ser pais e maridos." (Rousseau, 2004, p. 22)

Assim como se enganam ao acreditar que a infância só tem sentido se encarada a partir do modo de ser e pensar da vida adulta, Rousseau insiste em mostrar com alguns exemplos que o mesmo erro acontece na educação dessas crianças. Cita o caso do ensino das línguas e da história. Tanto em um caso como no outro, preceptores e pais se deixam enganar, acreditando que a criança, por repetir frases em outros idiomas, em especial citadas em línguas "mortas", ou narrando com entusiasmo a biografia de alguma figura histórica, estejam realmente aprendendo o significado de tudo isso. Rousseau enfatiza que a criança raciocina de outra forma, de tal modo que recebe tais informações, mas dão um sentido próprio segundo sua capacidade de compreensão.

Não, se a natureza dá ao cérebro de uma criança essa flexibilidade que o torna próprio para receber todo tipo de impressões, não é para que gravemos nele nomes de reis, datas, termos de heráldica, de esfera, de geografia e todas essas palavras sem sentido nenhum para sua idade, e sem nenhuma utilidade para qualquer idade que seja, com que massacramos sua triste e estéril infância, mas sim para que todas as ideias que ela pode conceber e lhe são úteis, todas as que se relacionam com sua felicidade e um dia devem ajudá-la a compreender seus deveres, nele se gravem desde cedo em caracteres indeléveis e lhe sirvam para que se oriente durante a vida de uma maneira que convenha a seu ser e a suas faculdades. (Rousseau, 2004, p. 127) 
Para Rousseau está claro que uma educação que visa formar no educando um sujeito autônomo, capaz de refletir e deliberar sobre as mais variadas situações que surgem na sua vida não deve ter como objetivo principal a transmissão de conteúdos. Rousseau se preocupou em destacar em diferentes partes do Emilio que tal atitude pedagógica, ao invés de formar indivíduos que pensam, formam o contrário disso, crianças e jovens tagarelas que, revestidos de certa erudição, reproduzem o verniz. da aparência de saber que esse filósofo tanto critica. O que importa não é fornecer conteúdos, mas criar situações em que o aluno sinta necessidade de conhecer novos saberes e, conduzido pelo preceptor, se torne curioso em aprender.

Tornai vosso aluno atento aos fenômenos da natureza e logo o tornareis curioso; mas, para alimentar sua curiosidade, nunca vos apresseis em satisfazê-la. Colocai questões ao seu alcance e deixai que ele as resolva. Que nada ele saiba porque lho dissestes, mas porque ele próprio compreendeu; não aprenda ele a ciência, mas a invente. Se alguma vez substituirdes em seu espírito a razão pela autoridade, ele já não raciocinará e não será mais do que o joguete da opinião dos outros. (Rousseau, 2004, p. 216)

No Emílio, o educador é quem prepara o caminho para a constituição do pensamento autônomo, respeitando, contudo, a autonomia já presente como possibilidade no aluno. "Todo o resto deve ser unicamente obra do discípulo, pois no mundo da vontade cada um só é verdadeiramente aquilo que autonomamente fez de si mesmo." (Cassirer, 1999, p. 118) Na educação de Emílio a consciência do não-saber é posta no processo de formação não como uma deficiência, mas como algo a ser superado sempre.

Emílio tem poucos conhecimentos, mas os que tem são seus de verdade; nada sabe pela metade. Dentre as poucas coisas que sabe, e sabe bem, a mais importante é que existem muitas coisas que ele ignora, mas pode um dia saber, muitas mais que outros homens sabem e ele nunca saberá em sua vida, e uma infinidade de outras que nenhum homem jamais saberá. Ele tem um espírito universal, não pelas luzes, mas pela faculdade de adquiri-las; um espírito aberto, inteligente, pronto para tudo e, como diz Montaigne, se não instruído, pelo menos instruível. (Rousseau, 2004, p. 281)

Um sistema de ensino com base no Emílio não se resumiria em deixar a criança fazer o que quisesse, como um animal selvagem, na natureza. Até mesmo porque Rousseau trabalha o tempo todo com situações hipotéticas que não foram e não são passíveis de aplicação prática. Conferindo valor à vontade coletiva, Rousseau pressupõe um povo soberano e autônomo e acredita que as virtudes e a vida em sociedade, para que seja boa, devem ser ensinadas, uma vez que para ele a educação é um hábito (Cf. Rousseau, 2004, p. 12). É um filósofo do dever ser e nos põe a refletir sobre como deveria ser diferente um sistema de ensino que realmente se preocupa com ensinar aos jovens que "viver é um ofício" que se deve aprender antes de preocupações com o papel que cada um desempenhará na sociedade (Cf. Rousseau, 2004, p. 15).

A sociedade na qual vivemos, não podemos negar, apresenta um grande interesse pela educação. Vemos na publicidade um grande esforço das autoridades 
públicas em convencer a população que muito se tem feito para melhorar a educação pública. Reformas e programas são criados a fim de melhorar o sistema. "Educar para vida", "para a cidadania" ou "para o mercado de trabalho", tanto faz, são alguns dos slogans presentes nos discursos políticos, tanto à esquerda quanto à direita. Estatísticas são apresentadas para mostrar que a educação, se não vai tão bem como se espera, tem "progredido" dentro do planejado. Os "gestores" estão seguros de que a educação que temos garante a "formação do cidadão". A filosofia de Rousseau nos faz duvidar de tudo isso. Em primeiro lugar, nos faz pensar sobre a própria definição do que é educação. Todas as vezes que falamos ou ouvimos falar sobre educação, na verdade se trata de escola. Como afirma Coêlho (2001, p. 55), "O próprio Ministério da Educação não vai além da Escola, nada mais é do que um Ministério das Escolas, ou melhor, Ministério das Coisas das Escolas." Pensar a educação significa, de fato, pensar a formação humana, não se tratando, pois, de instrumentalização da aprendizagem por meio de conteúdos, mas buscar dar forma ao humano que há como projeto em cada homem e mulher. Em segundo lugar, e inseparável da noção sobre o que é a educação, está a ideia do télos, do fim da educação. Rousseau nos mostra, para além de qualquer forma de utilitarismo, que não devemos buscar em outro lugar, senão no próprio homem e nas suas relações sociais a razão de ser dos processos formativos. Desse modo, não se trata de "formar para", mas formar o homem, fazer dele um cidadão. Aqui é preciso dar ênfase ao modo como hoje se entende cidadão, não passando nem perto do modo como Rousseau o concebia. Longe de ser reduzido a mero consumidor de produtos e imagens, o cidadão, como a própria palavra sugere, é aquele que participa ativamente da vida da cidade, essencialmente política, voltada para o interesse coletivo. Não se trata então de reformar a educação, nem procurar geri-la com mais eficiência, dentro de padrões de excelência racional, mas de colocar no horizonte dos processos educacionais, dentro e fora da escola, o homem e a vida coletiva como fim. Com isso, conteúdos, programas, currículos, "gestão democrática", perdem a sua dimensão instrumental e a ideia de reformar o que está aí perde o sentido. Não se trata mais de reformar, o que Rousseau nos sugere é um começar de novo, da raiz, dos fundamentos. Rousseau nos mostra que nenhuma discussão sobre a educação é fácil, pois está mais permeada de questões do que respostas. Talvez seja essa ainda a grande atualidade de uma filosofia da educação fundada na leitura crítica da obra de Rousseau, não dar respostas, mas por questões, desconfiar de qualquer teoria da educação que, mesmo que se diga crítica ou dialética, esteja mais preocupada em oferecer soluções.

\section{CONSIDERAÇÓES FINAIS: A AUTONOMIA DO ENSINO E O ENSINO PARA A AUTONOMIA}

Autonomia e servidão não compactuam. São antagônicas, portanto uma ótica instrumental da educação, determinando não apenas uma leitura rasa do mundo, mas também a sua perpetuação, nada mais estranho à educação rousseauniana do que esta apologia irresponsável do progresso instrumental. 
Tal como o soberano, na filosofia política de Rousseau, é o próprio povo na medida em que participa do todo que deve determinar o modo de ser da sociedade. Quanto à educação, dar-se-á de modo equivalente. Não se concebe uma educação para a autonomia se os sujeitos envolvidos, sem exceção, não participarem dos processos determinantes do fazer educativo.

Rousseau é sabidamente uma referência imprescindível a quem quer que se dedique a pensar a educação. A retomada deste autor no presente texto visa pensar elementos da filosofia de Rousseau que possam auxiliar a atividade do ensino numa perspectiva que colabora para a efetiva autonomia, tanto a discente quanto a docente. Não nos propusemos à formulação de algo parecido com o um manual prático de educação, o próprio Rousseau já nos alertava acerca do seu Emílio, negando-o enquanto um manual. A intenção final é nos dispormos de alguns elementos que sirvam como contribuição para o nosso repertório teórico que lidará com a atividade do ensino.

A liberdade que Rousseau visa no ato educativo não pode se desvencilhar de maneira alguma da concepção deste conceito na esfera política, isto é, no âmbito público. Ele é um teórico da "liberdade de si", mas esta autonomia não corresponde à uma omissão (ou mera observação) por parte daquele que se dedica à tarefa de ensinar. Não há nada mais pernicioso para a autonomia nos moldes rousseaunianos do que a mentalidade do laissez-faire. Liberdade é se submeter à lei que o próprio sujeito se dá. Tal conceituação tem sua origem na ideia do homem natural e, portanto, de sua liberdade natural quando ele era senhor de si e se bastava no mundo. No advento do social, mediante o pacto, tal liberdade é subjugada em favor de outra, melhor, mas não menos livre do ponto de vista estrutural. A liberdade civil diz respeito à integração dos indivíduos numa vontade geral da qual resultam as leis e, assim, obedecendo às leis oriundas da vontade geral, se obedece a si mesmo. Liberdade não é licenciosidade.

$\mathrm{Na}$ impossibilidade de formar-se o homem natural, tal como Rousseau afirmava, cabe à educação não se eximir da formação do cidadão. Portanto, qualquer contribuição rousseauniana que por ventura possa haver, necessariamente deve desembocar numa concepção de educação pública. Afirmando aqui o caráter inexcusável de um ensino proposto numa perspectiva ético-politica, num viés que pense a escola como partícipe do social e os alunos como partícipes da sociedade.

Por causa dessa concepção de educação é que não é possível determinar manuais precisos cujas regras estão apenas a ser aplicadas objetivando resultados previamente idealizados. E numa crítica de tal educação e sociedade instrumental que se origina o Emílio. Quando falamos em educação pública não queremos dizer com isto uma educação estatal, mas sim uma educação voltada aos interesses do coletivo, tal como as leis devem ser pensadas a partir desta mesma lógica. (CARVALHO, 2013, p.76) Desta forma, fica evidente que não se trata de uma reforma dos conteúdos. Os conteúdos sãos os mesmos, tratam do mundo comum e da história da humanidade. A questão é a apresentação e o sentido que se dá a isto que é feito - o ensino. Ensinar é propiciar experiências a partir da própria 
experiência do educador. Por isto não se pode pensar um ensino $d a$ autonomia, mas para ela. É um estar junto, em liberdade, no âmbito educativo, que permite experiências ricas do ponto de vista ético-político culminando num ethos para a vida. $\mathrm{O}$ ensinar a viver do Rousseau é simplesmente ensinar a potência autônoma e criativa que há na liberdade autêntica.

A importância do processo experimental do indivíduo é que ele mesmo se torne o sujeito de sua educação; a experiência é um elemento de mediação no processo educativo, visto que o homem para ser 'ele mesmo' tem que ir às coisas, situar-se entre elas e refletir suas relações objetivas e subjetivoobjetivas. (MATOS, Olgária apud CERIZARA, 1990, p.66)

Diante de um cenário da sociedade do espetáculo em que o efêmero torna-se critério de valor concomitante a um solapamento da memória em razão de sua virtualização em suportes eletrônicos, disso não decorre outra coisa que o empobrecimento de experiências autênticas que transformariam, de fato, um homem em cidadão.

Nosso verdadeiro estudo é o da condição humana. Aquele de nós que melhor souber suportar os bens e os males desta vida é, para mim, o mais bem educado; donde se seque que a verdadeira educação consiste menos em preceitos do que em exercícios. Começamos a nos instruir quando começamos a viver. (ROUSSEAU, 2004, p.16)

Rousseau foi um filósofo e, como tal, sua autenticidade está na capacidade dos seus escritos reverberarem em nós, estimulando novas perguntas e refazendo tantas outras que julgávamos respondidas. Concordamos mais uma vez com Starobinski da importância do resgate desta postura: refazer perguntas. Ele diz "mais do que dar respostas, tentamos resgatar as perguntas e os conflitos suscitados por Rousseau ao longo do livro." (STAROBINSKI apud CERIZARA, 1990, p.21) Como um crítico póstumo de seu próprio tempo, não se exaltando no progresso em si, menos ainda na pura racionalidade. Repitamos sua atitude e não façamos de Rousseau o que ele não fez de si. Um modelo.

Podemos encerrar reafirmando que "Emílio não é um exemplo, nem uma máxima rígida. Emílio não existe, sua história não pretende senão levar a refletir." (BURGELIN apud CERIZARA, 1990, p.53) E pensar a autonomia em tempos nos quais a educação e, sobretudo, a escola, sofrem ataques de pautas instrumentalistas que atendem ao interesse do mercado produtivo e neoliberais que atendem ao mercado financeiro, para não falar de um movimento que intenta separar a educação da responsabilidade política inerente à atividade docente, minando sua própria razão de ser. Pensar a nossa autonomia nesses contextos já é um princípio de exercê-la. 


\section{REFERÊNCIAS}

ARENDT, H. A condição humana. Tradução de Roberto Raposo. 10. ed. Rio de Janeiro: Forense Universitária, 2009.

A vida do espírito: o pensar, o querer, o julgar. Tradução Antônio Abranches e outros. 4. ed. Rio de Janeiro: Relume Dumará, 2000.

CALVINO, I. Por que ler os clássicos. Tradução de Nilson Moulin. 2. ed. São Paulo : Companhia das Letras, 2005.

CARVALHO, José Sergio. Reflexões sobre educação, formação e esfera pública. Porto Alegre: Penso, 2013.

CASSIRER, E. A questão Jean-Jacques Rousseau. Tradução de Erlon José Paschoal. São Paulo: Ed. UNESP, 1999.

CASTORIADIS, C. Encruzilhadas do labirinto III: o mundo fragmentado. Tradução de Rosa Maria Boaventura. Rio de Janeiro: Paz e Terra, 1992.

. Uma sociedade à deriva. Tradução de Cláudia Berlinger. Aparecida: Idéias \& Letras, 2006.

CERIZARA, Beatriz. Rousseau: a educação na infância. São Paulo: Scipione, 1990.

COÊLHO, I. M. Filosofia e educação. In: PEIXOTO, A. J (org.). Filosofia, educação e cidadania. Campinas: Alínea, 2001. p. 19-70.

DESNÉ, R. A filosofia francesa no século XVIII. In: CHÂTELET, F. História da

filosofia - idéias, doutrinas: o Iluminismo. Rio de Janeiro: Zahar Editores, 1974. p. 71 107.

FRANÇA, F. C. T. Criação e dialética: o pensamento histórico-político de Cornelius Castoriadis. São Paulo: EDUSP, Brasiliense, 1996.

GUSDORF, G. Les principes de la pensée au siècle des Lumières. Paris: Payot, 1971.

KANT, I. Resposta à pergunta: Que é “Esclarecimento”? In:

Tradução de Floriano de Sousa Fernandes. 5. ed. Petrópolis: Vozes, 2009.

LE GOFF, J. Para um novo conceito de idade média: tempo, trabalho e cultura no ocidente. Tradução Maria Helena da Costa Dias. Lisboa: Estampa: 1993.

LIMA VAZ, H. C. Antropologia filosófica. V. 1. 7. ed. São Paulo: Loyola, 2004.

ROUSSEAU, J.-J. Discurso sobre a origem e os fundamentos da desigualdade entre os homens: precedido de discurso sobre as ciências e as artes. 3. ed. São Paulo: Martins Fontes, 2005. 
O contrato social e outros escritos. Tradução de Rolando Roque da Silva. 4. ed. São Paulo: Cultrix, 1978.

. O Emílio ou Da Educação. Tradução de Roberto Leal Ferreira. 3. ed. São

Paulo: Martins Fontes, 2004.

STAROBINSKI, J. Jean-Jacques Rousseau: a transparência e o obstáculo. Tradução de Maria Lúcia Machado. São Paulo: Companhia das Letras, 1991.

VALLÉE, C. Hannah Arendt: Sócrates e a questão do totalitarismo. Tradução de Armando Pereira da Silva. Lisboa: Instituto Piaget, 1999.

VAZ, H. C. L. Antropologia filosófica. Vol. 1. 7. ed. São Paulo: Loyola, 2004. 